\title{
CONTROLES INTERNOS E SUA RELAÇÃO COM O DESEMPENHO ORGANIZACIONAL
}

Suzete Antonieta Lizote ${ }^{1}$

Grazieli Vitali $^{1}$

Charlize De Morais Noval $^{1}$

Sueli Maria Kolassa ${ }^{1}$

${ }^{1}$ Universidade do Vale do Itajaí 


\section{CONTROLES INTERNOS E SUA RELAÇÃO COM O DESEMPENHO ORGANIZACIONAL}

Resumo: Este estudo tem como objetivo verificar se os controles internos de contas a receber e contas a pagar das empresas que fabricam roupas íntimas e moda praia, localizadas em Ilhota/SC, se relacionam com o desempenho organizacional. Os procedimentos metodológicos adotados foram de natureza quantitativa e aplicada. Em relação ao seu objetivo, considera-se descritivo, sendo feito a partir dos dados obtidos em uma survey com questionário. A análise estatística incluiu a descrição das características da amostra, através da frequência com que ocorrem as informações solicitadas, e o uso da análise de correlação. Usando análise de correspondência foram gerados os escores fatoriais e com eles avaliaram-se as associações entre os constructos. Os resultados indicam que o uso dos controles de contas a receber e contas a pagar tem uma relação positiva e significativa com o desempenho, mas apresentam diferenças em função dos fatores a partir do qual os escores foram gerados.

Palavras-chave: Controles internos. Contas a pagar. Contas a receber. Desempenho.

\section{Introdução}

Atualmente as pequenas e médias empresas estão percebendo a relevância do controle interno como ferramenta de gestão, pois o mesmo se mostra eficiente ao evitar a ocorrência de erros e procedimentos ilegais ou fraudulentos. De acordo com Ritta (2010, p. 66) "A utilização dos controles internos teve início com a necessidade de maior controle das operações realizadas, pois com a expansão dos mercados, e o desenvolvimento das atividades, controle dos seus diversos setores se tornou mais complexo".

O controle interno representa um conjunto de procedimentos, métodos ou rotinas com a finalidade de proteger os ativos, produzir dados contábeis confiáveis e auxiliar a administração na condução ordenada dos negócios. Para Ge e McVay (2007), a adequada estruturação de um sistema de controle interno tende a reduzir: (i) a ocorrência de fraudes e erros, (2) o risco e custos de auditoria, (3) os custos de agência, (4) republicação das demonstrações, entre outros. Neste sentido, Lopes, Marques e Louzada (2019), afirmam que os controles internos estabelecem as normas e procedimentos específicos a serem utilizados pelos empregados e gestores no desenvolvimento das suas atividades.

Os controles internos, se forem bem coordenados, podem oferecer apoio administrativo para mensurar, monitorar, avaliar e adequar os procedimentos contábeis e operacionais. As entidades tais como empresas públicas, privadas ou que prestam serviços de caráter público sem fins lucrativos, buscam cada vez mais aperfeiçoar a aplicação de seus controles. Contudo, estudos como os de Garcia, Kinzler e Rojo (2014) e Postiglione e Silva (2016) mostram que um sistema de controle interno adequado ainda não ocorre com a mesma frequência e eficácia nas micro e pequenas empresas

Diante destas colocações, emerge a seguinte pergunta de pesquisa: Os controles internos das contas a receber e a pagar das empresas do segmento de moda íntima e linha praia localizadas no município de Ilhota/SC influenciam no desempenho organizacional? Para responder a essa 
indagação, definiu-se como objetivo geral, verificar se os controles internos de contas a receber e contas a pagar das empresas que fabricam roupas íntimas e moda praia, localizadas em Ilhota/SC, se relacionam com o desempenho organizacional Para realizar a análise dessas associações se estabeleceram os seguintes objetivos específicos: a) identificar se os controles internos das contas a receber e a pagar estão sendo realizados de acordo com as normas de auditoria; b) mensurar o desempenho organizacional na percepção dos gestores; e, c) avaliar o relacionamento entre os controles internos levantados e o desempenho organizacional.

$\mathrm{Na}$ gestão empresarial, a falta de organização causa impactos negativos tanto em termos de lucratividade quanto de imagem, influenciando desta forma, no desempenho da entidade. Salientam Lopes, Marques e Louzada (2019) que um dos meios eficientes para assegurar que a empresa tenha um desempenho satisfatório, é o uso contínuo dos sistemas de controles internos. Estes proporcionam segurança para a administração que busca atingir suas metas e objetivos. Um sistema de controles internos também tem como finalidade tranquilizar os usuários das informações, proporcionando confiabilidade dos seus demonstrativos financeiros. Assim, constata-se que é necessária a existência de controles internos também para o setor financeiro, no qual são geradas informações diárias sobre a saúde financeira da empresa.

A escolha por este agrupamento de negócios se deve ao fato de que estado de Santa Catarina, na região Sul, nos últimos vinte anos, vem passando por grandes transformações no setor têxtil, com destaque para o município de Ilhota, que depois da crise do setor nos anos 90, sofreu uma evolução e hoje ostenta o título de Capital Catarinense de Moda Íntima e Praia. A indústria local produz cerca de 500 mil peças por mês. Grande parte da produção é adquirida pelo mercado interno, com as regiões Sul e Sudeste e, em torno de $10 \%$ da fabricação é destinada ao mercado internacional.

A realização deste trabalho, para as empresas visa oferecer uma gama de informações sobre controle interno, evidenciando que sua eficiente aplicação proporcionará melhoria dos controles e processos, minimizando os riscos e otimizando suas atividades e resultados. Para a comunidade acadêmica é uma oportunidade de aprofundar conhecimentos da temática abordada, bem como visualizar como ocorre na prática a aplicabilidade dos controles internos. $\mathrm{O}$ artigo está estruturado em cinco seções, iniciando com esta introdução. A segunda seção apresenta o referencial teórico; a abordagem metodológica é apresentada na seção seguinte; as análises e discussão dos dados estão evidenciadas na seção quatro. Na quinta são feitas as considerações finais da pesquisa e por último, é disponibilizado o referencial bibliográfico.

\section{Referencial Teórico}

Neste tópico aborda-se os temas controle interno e desempenho organizacional.

\subsection{Controles Internos}

A gestão organizacional, para atingir os objetivos propostos com segurança e credibilidade, necessita de controles internos. De acordo com Crepaldi e Crepaldi (2017), o controle interno representa, em uma organização, o conjunto de procedimentos, métodos ou rotinas com o objetivo de proteger os ativos, produzir dados contábeis confiáveis e ajudar a administração na condução ordenada dos negócios da empresa. 
De acordo com a AICPA - American Institute of Certified Public Accountants (2016), os controles internos podem ser definidos como aqueles instrumentos e sistemas desenvolvidos com a finalidade de se mitigar riscos operacionais que impliquem em fraudes ou erros. Eles possibilitam que as operações realizadas pela companhia sejam completas e adequadamente divulgadas, detectando-se previamente a ocorrência de tais eventos e propondo soluções para corrigi-las

Barbosa e Santos (2018), esclarecem que a existência de controles internos eficientes possibilita aos gestores eficientes tomada de decisões, contribuindo, desta forma, para evitar desperdícios por meio da melhor utilização de recursos, assim como para de detectar e impedir erros e fraudes. Desse modo, a preocupação com a adequada estruturação do sistema de controle interno deve ser constante. Fourie e Ackermann (2013), salientam que desde os anos de 2000 com casos de fraudes ocorridos, os quais geraram grandes perdas aos investidores, as empresas, órgãos não governamentais e reguladores têm destinado esforços para estimular a adequada estruturação dos controles internos. estímulo a adequada estruturação e uso dos controles internos. Segundo Tysiac (2012), por 20 anos, o framework do Committee of Sponsoring Organizations of Treadway (COSO) foi utilizado como base. Suas diretrizes estabelecem que no processo de estruturação do sistema de controle interno as empresas deverão se preocupar: (1) com a eficiência e eficácia operacional, (2) confiabilidade das informações e prestações de contas e, (3) conformidade ou cumprimento das exigências legais, éticas e morais.

Os estudos de Leite e Pinheiro (2015) investigaram a percepção dos auditores e auditados acerca dos efeitos da SOX sobre a estrutura de controle interno com 50 empresas auditadas e 93 auditores independentes que atuavam em Big4. Os resultados evidenciaram que, em geral, tanto os auditores, quanto as empresas auditadas verificaram melhorias substanciais com a adoção da SOX, sugerindo que as informações divulgadas passassem a ser mais precisas em decorrência do fortalecimento dos controles internos.

Jokipii (2010) argumenta que quatro fatores têm sido observados como relevantes na efetividade dos controles internos: (i) estratégia, (ii) o tamanho da firma, (iii) a estrutura organizacional e (iv) a percepção de incerteza. Uma implicação direta disso é que por exemplo, um ambiente de incerteza fará com que as partes envolvidas (stakehoders e shareholders) exigirão uma divulgação mais robusta de informações acerca das deficiências dos controles internos, pois essas podem aumentar ou reduzir ainda mais suas percepções de riscos.

Assing, Alberton e Tesch (2016) analisaram o comportamento das fraudes ocorridas em uma amostra de 100 empresas nos anos de 2002 e 2004 e verificaram que entre os principais motivos de crescimento dos casos de fraude, destacaram-se: (1) perdas dos valores sociais e morais, (2) impunidade e (3) insuficiência de sistemas de controles.

Conforme exposto, fica evidente que os controles internos são ferramentas que os gestores utilizam para garantir que as informações geradas sejam confiáveis e estejam de acordo com as normas e políticas pré-estabelecidas.

\subsection{Desempenho Organizacional}

Os indicadores de desempenho configuram-se como instrumentos capazes de fornecer informações para o processo de tomada de decisões. Para Dutra (2003) avaliar o desempenho 
consiste em atribuir valor àquilo que uma organização considera importante diante dos seus objetivos estratégicos.

Diversos são os motivos que levam as entidades a mensurarem seu desempenho organizacional. Entre eles, Nascimento; Bortoluzzi e Ensslin (2011) destacam: poder realizar comparações de desempenho com concorrentes ou organizações de outros ramos; poder demonstrar aos investidores qual o potencial de retorno de seus investimentos; e poder verificar periodicamente se as estratégias organizacionais de curto, médio ou longo prazo estão sendo cumpridas.

Para dar suporte às decisões estratégicas da organização sua mensuração, segundo Bortoluzzi; Ensslin e Ensslin (2010), deve considerar alguns elementos importantes, quais sejam: levar em consideração as particularidades de cada organização; considerar indicadores financeiros e não financeiros, ou seja, os aspectos tangíveis e intangíveis; ligar os objetivos estratégicos com os objetivos operacionais; e, construir um processo de comunicação que permita a todos os níveis organizacionais identificar de forma clara e holística os objetivos que a organização está idealizando.

A avaliação de desempenho pode ser conceitualmente definida como um sistema equilibrado e dinâmico, composto por indicadores capazes de suportar o processo decisório por meio de coleta, tratamento e análise da informação (NEELY, ADAMS; KENNERLEY, 2002). Desta forma, conforme destacam Melnyk et al, (2014), os indicadores são medidas de desempenho que quantificam o que está acontecendo e permitem a comparação com o padrão de desempenho esperado. Com isso, indicam o que é considerado bom ou mau desempenho, orientando a direção da organização e as consequências de se estar acima ou abaixo dos objetivos e das estratégias estabelecidas.

Macedo e Corrar (2010), por sua vez, destacam que a avaliação do desempenho das empresas tem se destacado na gestão das organizações, pois seja contábil ou de mercado, é fundamental para sua sobrevivência. Sua análise, segundo Brandt; Kroenke e Pletesch (2018) é de suma importância, por ser essencial para o controle gerencial dos negócios.

$\mathrm{O}$ crescimento do interesse pelas medidas de desempenho organizacional deve-se as importantes mudanças tanto no ambiente empresarial quanto nas estratégias adotadas. Neste sentido Ramos e Souza (2018, p. 43) esclarecem que "A avaliação de desempenho das organizações é uma atividade essencial na gestão, pois os novos desafios, complexidade de relações e a dinâmica do mundo dos negócios cada vez mais tecnológica e competitiva".

O desempenho, segundo Machado; Machado e Holanda (2007) pode ser mensurado através de duas formas: subjetivamente, a que está relacionado ao desempenho das organizações segundo a sua própria expectativa e a segunda opção é analisá-lo de forma objetiva, baseado em medidas absolutas de desempenho. Neste estudo, escolheu-se utilizar medidas subjetivas de desempenho, trabalhando com a percepção dos gestores das empresas de moda íntima e linha praia estabelecidas em Ilhota/SC.

\section{Metodologia}

A busca por delineamentos que orientem o trabalho de pesquisa envolve a definição do método e dos procedimentos a serem aplicados. É preciso que se desenvolvam mecanismos que possam conferir maior nível de precisão aos fatos. Assim, é fundamental estabelecer uma metodologia de pesquisa para a coleta, a análise e a interpretação dos dados. 
O estudo, em relação aos seus objetivos, define-se como uma pesquisa descritiva uma vez que busca apresentar uma realidade (VERGARA, 1998) e verificar um modelo. Do ponto de vista da forma de abordagem do problema, classifica-se como quantitativa, pois segundo Severino (2000, p. 46), "a pesquisa quantitativa considera que tudo pode ser quantificável, o que significa traduzir em números opiniões e informações para classificá-las e analisá-las”.

Quanto aos procedimentos, pode ser classificada como uma pesquisa de campo, sendo conduzido um levantamento com auxílio de questionário. O instrumento de coleta de dados foi aplicado pessoalmente aos responsáveis pelo setor financeiro das empresas de moda íntima e praia de Ilhota, Santa Catarina, no qual o controle interno é tratado especificamente no contas a receber e a pagar.

Os dados foram levantados por meio de um questionário estruturado, composto por quatro blocos. No primeiro se requeria que o respondente preenchesse seus dados e os da empresa. Os itens pessoais solicitados eram: cargo ou função; tempo de serviço; formação; e, sexo. Já os relativos à empresa incluíram: a classificação segundo considerasse o tamanho, entre micro, pequena, média ou grande; tipo de administração a selecionar, entre familiar, profissional ou mista; atividade principal, definida como comércio, indústria ou ambos; tipo de produto comercializado e/ou fabricado; e, número de funcionários que trabalham na firma.

$\mathrm{O}$ segundo e o terceiro blocos compreendiam um conjunto de quinze questões em cada para serem respondidas por sim ou não. As perguntas de cada bloco estavam dirigidas a levantar se as organizações se ajustavam às normas de auditoria quanto aos controles internos das contas a receber e a pagar respectivamente. Por fim no quarto bloco se solicitava que o respondente declarasse sua satisfação com os sete indicadores de desempenho usando uma escala Likert de sete pontos. As afirmativas que foram disponibilizadas faziam referência ao desempenho em relação ao concorrente mais próximo. Elas trataram do lucro líquido, vendas totais, realização de objetivos financeiros, metas de emprego e pessoal, satisfação dos clientes, retenção de clientes e desempenho geral.

Os dados obtidos foram organizados em uma planilha eletrônica Excel® a partir da qual se fizeram todas as análises descritivas com base nas frequências. Posteriormente a matriz se importou para o software Statistica ${ }^{\circledR}$ com o que foi feita uma análise de correspondência simples para os blocos de contas a receber, a pagar e o relativo ao desempenho. De cada uma das soluções se geraram os escores fatoriais dos dois primeiros fatores e com eles fez-se a análise de correlação. Ou seja, para avaliar as possíveis associações entre esses constructos, expressos pelos escores, se calculou o coeficiente de correlação entre os blocos dos controles internos com os aqueles do desempenho.

\section{Resultados e Análise dos Dados}

A amostra levantada esteve composta por 68 questionários recebidos, dos quais foram 30 respondentes do gênero feminino e 38 do masculino. As empresas foram consideradas como microempresas em 34 oportunidades, 20 como médias e 14 pequenas empresas. Entretanto, a autoclassificação não respeita os números de funcionários que se utilizam para aquelas categorias. A média geral foi 19 empregados com um mínimo de 3 e um máximo de 70. 
A maioria das empresas é de gestão familiar (52), enquanto 8 tem gestão profissional e o mesmo número são mistas. Caracterizaram-se como empresas comerciais 10 organizações, 33 como indústria e 25 realizando ambas as atividades, as industriais e as comerciais.

Ao observar seu grau de instrução se verifica que 18 declararam ter completado o ensino fundamental e 14 o ensino superior completo. A maioria dos gestores, 32, tem cursado o ensino médio. Dos 4 últimos respondentes que completam a base de dados, 2 declararam ter ensino superior incompleto e 2 estar ainda cursando.

A seguir da caracterização da amostra e buscando atender o primeiro objetivo específico se avaliou como eram atendidas as normas de auditoria em relação às contas a receber e contas a pagar. No questionário havia dois blocos com 15 questões referidas a esses temas. Os resultados são apresentados nos Quadros 01 e 02 onde se listam as questões, o que corresponde à resposta esperada segundo a norma e a porcentagem de acertos dos respondentes em relação ao total de respostas.

No quadro 01 apresentam-se os resultados referentes ao contas a receber.

\begin{tabular}{|c|c|c|c|c|}
\hline \multirow{2}{*}{$\mathbf{N}^{\mathbf{o}}$} & \multirow{2}{*}{ Pergunta } & \multicolumn{2}{|c|}{ Norma } & \multirow{2}{*}{$\begin{array}{l}\text { Porcentagem } \\
\text { de acertos }\end{array}$} \\
\hline & & Sim & Não & \\
\hline 1 & $\begin{array}{l}\text { As contas à receber são reais e representam direitos efetivos contra os } \\
\text { devedores? }\end{array}$ & $\mathrm{x}$ & & $55,88 \%$ \\
\hline 2 & Existem senhas de acesso no sistema de contas a receber? & $\mathrm{x}$ & & $75,00 \%$ \\
\hline 3 & O crédito concedido aos clientes necessita de autorização? & $\mathrm{x}$ & & $100,00 \%$ \\
\hline 4 & $\begin{array}{l}\text { As contas a receber são contabilizadas de acordo com as Normas de } \\
\text { Contabilidade }\end{array}$ & $\mathrm{x}$ & & $75,00 \%$ \\
\hline 5 & $\begin{array}{l}\text { Existe autorização para a concessão de descontos e/ou dispensa de } \\
\text { juros? }\end{array}$ & $\mathrm{x}$ & & $52,94 \%$ \\
\hline 6 & $\begin{array}{l}\text { As baixas de duplicatas a receber são realizadas com documentos } \\
\text { hábeis e comprobatórios? }\end{array}$ & $\mathrm{x}$ & & $100,00 \%$ \\
\hline 7 & $\begin{array}{l}\text { O responsável pelo contas a receber tem autorização para baixa por } \\
\text { devolução ou perda? }\end{array}$ & & $\mathrm{x}$ & $51,47 \%$ \\
\hline 8 & $\begin{array}{l}\text { Há políticas de controle de duplicatas a receber vencidas e não } \\
\text { recebidas? }\end{array}$ & $\mathrm{x}$ & & $79,41 \%$ \\
\hline 9 & $\begin{array}{l}\text { Há possibilidade de inclusão de compromisso no contas a receber sem } \\
\text { autorização? }\end{array}$ & & $\mathrm{x}$ & $80,88 \%$ \\
\hline 10 & $\begin{array}{l}\text { As alterações de vencimento no contas a receber são devidamente } \\
\text { registradas e aprovadas? }\end{array}$ & $\mathrm{x}$ & & $100,00 \%$ \\
\hline 11 & $\begin{array}{l}\text { Os recebimentos do contas a receber são efetuados diretamente na } \\
\text { conta caixa/banco? }\end{array}$ & $\mathrm{x}$ & & $27,94 \%$ \\
\hline 12 & $\begin{array}{l}\text { Os recebimentos do contas a receber são retidos por alguns dias antes } \\
\text { da efetiva baixa? }\end{array}$ & & $\mathrm{x}$ & $36,76 \%$ \\
\hline 13 & Há procedimentos de segurança nos recebimentos por cheques? & $\mathrm{x}$ & & $26,47 \%$ \\
\hline 14 & $\begin{array}{l}\text { Há realização de conciliações periódicas do contas a pagar com a } \\
\text { contabilidade? }\end{array}$ & $\mathrm{x}$ & & $17,65 \%$ \\
\hline 15 & $\begin{array}{l}\text { O responsável pelas contas a receber também é responsável pela } \\
\text { conciliação bancária? }\end{array}$ & & $\mathrm{x}$ & $11,76 \%$ \\
\hline
\end{tabular}

Quadro 01 - Porcentagem de respostas certas quanto às normas de auditoria para as contas a receber 
Conforme o questionário exposto no Quadro 01, que apresenta o percentual de acertos dos respondentes com relação às contas a receber, efetuaram-se às análises descritas a seguir. As questões 3, 6 e 10 do quadro 01 obtiveram um percentual de 100\% de acerto. Constata-se, portanto que todos os entrevistados têm grande conhecimento referente aos créditos concedidos aos clientes, a importância de comprovação de documentos hábeis e confiáveis para realizar as baixas das duplicatas e que as alterações de vencimento no contas a receber devem ser devidamente registradas e aprovadas. Demonstrando assim, consonância com as normas pertinentes.

Em contrapartida na questão 15 , o percentual de acerto foi de apenas $11,76 \%$. Ou seja, a maior parte dos entrevistados apontou que o responsável pelas contas a receber também é o responsável pela conciliação bancária, demonstrando total divergência com as normas de auditoria. Portanto, é requerida maior atenção neste aspecto.

Nas perguntas 1, 5 e 7 os acertos e erros ficaram equilibrados, sendo: 55,88\%; 52,94\%; e, $51,47 \%$ respectivamente. Estes resultados demonstraram que pouco mais da metade dos respondentes sabem que: as contas a receber são reais e representam direitos efetivos contra devedores (questão 1); existe autorização para a concessão de descontos e/ou dispensa de juros (questão 5); e, o responsável pelo contas a receber não tem autorização para baixa por devolução ou perda (questão 7). Com isso podemos observar os erros que podem ocorrer na gestão das empresas pela inobservância das regulamentações pertinentes.

Já nas questões 2 e 4, o percentual de acertos ficou em $75 \%$ para as duas. Isto é, a maioria possui o conhecimento que existem senhas de acesso no sistema de contas a receber como também que as contas a receber são contabilizadas de acordo com as Normas de Contabilidade.

Elevam-se os índices de acertos nas interrogativas 8 e 9, gerando percentuais de 79,41\% e $80,88 \%$ respectivamente. Verifica-se, portanto, através dos dados coletados que, grande parte tem segurança em afirmar que há políticas de controle de duplicatas a receber vencidas e não recebidas e que não há possibilidade de inclusão de compromisso no contas a receber sem autorização.

Nas questões 11, 13 e 14, os percentuais de acertos caem drasticamente, ficando abaixo de $30 \%$, ou seja, $27,94 \%$; 26,47\% e, $17,65 \%$ respectivamente. Isso mostra o pouco domínio dos entrevistados no que tange sobre se há realização de conciliações periódicas do contas a pagar com a contabilidade; se há procedimentos de segurança nos recebimentos de cheques; e se os recebimentos do contas a receber são efetuados diretamente na conta caixa/banco, sendo SIM para todos os 3 questionamentos.

Na questão 12, o percentual de acerto foi de $36,76 \%$, identificando assim, que a maior parte das empresas entrevistadas possui os recebimentos retidos por alguns dias antes da baixa ser efetivada, demonstrando estar contra as normas de auditoria.

$\mathrm{Na}$ análise das contas a receber, é claramente visível que a grande parte de desacordo com as normas de auditoria está no procedimento de segurança no caso de recebimento com cheque, sendo que a norma informa necessidade desse procedimento ser efetuado para evitar possíveis perdas. O nível de conhecimento dos entrevistados é muito baixo em relação aos procedimentos contábeis, visto que poucos entrevistados sabem da importância da conciliação das contas a receber com a contabilidade.

De acordo com o questionário exibido no Quadro 02, se apresenta o percentual de acertos dos respondentes com relação às contas a pagar. 


\begin{tabular}{|c|c|c|c|c|}
\hline \multirow{2}{*}{$\mathbf{N}^{\mathbf{o}}$} & \multirow{2}{*}{ Pergunta } & \multicolumn{2}{|c|}{ Norma } & \multirow{2}{*}{$\begin{array}{l}\text { Porcentagem } \\
\text { de acertos }\end{array}$} \\
\hline & & Sim & Não & \\
\hline 1 & As contas à pagar são reais e representam efetivamente as obrigações? & $\mathrm{x}$ & & $55,88 \%$ \\
\hline 2 & Existem senhas de acesso no sistema de contas a pagar? & $\mathrm{x}$ & & $75,00 \%$ \\
\hline 3 & Há revisão e autorização dos pagamentos? & $\mathrm{x}$ & & $82,35 \%$ \\
\hline 4 & $\begin{array}{l}\text { As baixas de duplicatas à pagar são realizadas com documentos } \\
\text { hábeis e comprobatórios? }\end{array}$ & $\mathrm{x}$ & & $100,00 \%$ \\
\hline 5 & $\begin{array}{l}\text { O responsável pelo contas a pagar tem autorização para baixa por } \\
\text { devolução? }\end{array}$ & & $\mathrm{x}$ & $51,47 \%$ \\
\hline 6 & Há controle de pagamentos para evitar atrasos? & $\mathrm{x}$ & & $100,00 \%$ \\
\hline 7 & Há políticas para as duplicatas a pagar vencidas? & $\mathrm{x}$ & & $57,35 \%$ \\
\hline 8 & $\begin{array}{l}\text { Há possibilidade de inclusão de compromissos no contas a pagar sem } \\
\text { autorização? }\end{array}$ & & $\mathrm{x}$ & $80,88 \%$ \\
\hline 9 & $\begin{array}{l}\text { As alterações de vencimento no contas a pagar são devidamente } \\
\text { registradas e aprovadas? }\end{array}$ & $\mathrm{x}$ & & $100,00 \%$ \\
\hline 10 & Os juros são pagos com autorizações? & $\mathrm{x}$ & & $42,65 \%$ \\
\hline 11 & $\begin{array}{l}\text { Existem duas assinaturas escritas ou eletrônicas para efetuar o } \\
\text { pagamento? }\end{array}$ & $\mathrm{x}$ & & $41,18 \%$ \\
\hline 12 & Existe a possibilidade de um pagamento ser feito em duplicidade? & & $\mathrm{x}$ & $100,00 \%$ \\
\hline 13 & $\begin{array}{l}\text { O responsável pelo contas a pagar também é responsável pela } \\
\text { conciliação bancária? }\end{array}$ & & $\mathrm{x}$ & $11,76 \%$ \\
\hline 14 & $\begin{array}{l}\text { Há realização de conciliações periódicas do contas a pagar com a } \\
\text { contabilidade? }\end{array}$ & $\mathrm{x}$ & & $17,65 \%$ \\
\hline 15 & $\begin{array}{l}\text { As contas a pagar são contabilizadas de acordo com as Normas de } \\
\text { Contabilidade }\end{array}$ & $\mathrm{x}$ & & $75,00 \%$ \\
\hline
\end{tabular}

Quadro 02 - Porcentagem de respostas certas quanto às normas de auditoria para as contas a pagar

As questões 4, 6, 9 e 12 do quadro 02 obtiveram um percentual de acerto de $100 \%$, destacando assim o conhecimento que os entrevistados possuem referente ao procedimento de baixa das duplicatas e o controle de contas a pagar no que se refere aos atrasos dos pagamentos, alteração de vencimento no contas a pagar e seus registros e pagamentos em duplicidade, evitando possíveis perdas. Ao contrário da questão 13, onde percentual de acerto foi de apenas $11,76 \%$, ou seja, a maior parte dos respondentes acham que o responsável pelo contas a pagar também é o responsável pela conciliação bancária, demonstrando total divergência com as normas de auditoria.

A interrogativa 14, que trata de conhecimentos básicos das práticas contábeis, obtive percentual de $17,65 \%$. Pode-se afirmar que a maioria dos entrevistados não possui conhecimento e não realizam as conciliações das contas a pagar com a contabilidade.

A questão 5 obteve um percentual de acerto de $51,47 \%$. A primeira questão $55,88 \%$ e a questão 7 teve $57,35 \%$ de acertos. Tornando visível que pouco mais da metade dos entrevistados responderam em consonância com as normas vigentes, mostrando certo desconhecimento sobre a responsabilidade pelo contas a pagar e a autorização para baixa por devolução; a efetividade das obrigações quanto as contas a pagar e sua real existência; e, políticas para duplicatas a pagar vencidas. 
A questão 10 obteve um percentual de acerto de $42,65 \%$, com isso, constata-se que maior parte dos entrevistados pagam os juros sem autorização de um supervisor. Na questão 11 , o percentual de acerto foi de $41,18 \%$. Poucas empresas possuem duas assinaturas para efetuar os pagamentos, constatando assim, que grande parte vai contra as normas de auditoria e possuem muito desconhecimento das mesmas.

As questões 2 e 15 obtiveram o mesmo percentual, 75\%. Desta forma, constata-se que a grande parte das empresas possuem senhas de segurança e realizam as contas a pagar de acordo com as Normas de Contabilidade. Neste quesito, os conhecimentos mostraram um nível elevado.

Na questão 3, o percentual de acerto foi de $82,35 \%$. Destacando que, ainda que sejam poucas, existem empresas que não realizam a revisão e autorização dos pagamentos. Já na questão 8 , o percentual de acerto foi de $80,88 \%$., demonstrando que a maioria das empresas tem possibilidade de inclusão de compromissos no contas a pagar sem autorização.

$\mathrm{Na}$ análise das contas a pagar, deve-se chamar a atenção e tomar cuidado nos pagamentos de juros, pois uma parte significativa dos entrevistados o efetua sem autorização. Como também em regras básicas da contabilidade, como: a responsabilidade pela conciliação bancária e o contas a pagar; conciliações periódicas do contas a pagar com a contabilidade e assinaturas eletrônicas ou escritas para efetuar pagamentos. Os demais itens estão em sua maioria de acordo com as normas de auditoria.

Com os dados levantados para as contas a receber (CR) e contas a pagar (CP), segundo as questões que se exibem nos Quadros 01 e 02 , se geraram duas novas bases de dados com valores 0 e 1 conforme a resposta dada estivesse errada ou certa. A partir dessas duas matrizes se realizaram as análises fatoriais de correspondências simples e retiveram-se os fatores segundo o critério gráfico de Cattell (1966). Para CR foram dois fatores e para CP três.

Para contas a receber o primeiro fator (CR1) expressa as relações das questões 1 e 13 com um número alto de acertos e as questões 9 e 14 com poucos acertos. $O$ fator segundo (CR2), por sua parte, mostra o vínculo das questões 12 e 11, com muitos e poucos acertos respectivamente. No caso das contas a pagar os três fatores retidos manifestam as relações no fator 1 (CP1) entre as questões 1,7 e 11 com um número alto de acertos e as de número 8 e 14 com poucos; no fator 2 (CP2) com um número similar e baixo de acertos associam-se as questões 10 e 11 e, no fator 3 (CP3), as questões 8 e 14, também ambos com poucos acertos.

Com os dados do desempenho, mensurado de maneira comparada com relação ao concorrente mais próximo, usando uma escala Likert de concordância com sete pontos, se fez também uma análise de correspondências simples. Obtiveram-se neste caso dois fatores segundo o mesmo critério de Cattell. O primeiro fator (D1) refere-se à satisfação e retenção de clientes junto com a realização dos objetivos financeiros e o lucro líquido. Já o segundo fator (D2) contempla as vendas totais e o cumprimento das metas de emprego e pessoal.

Gerados os escores fatoriais para os fatores retidos nos três constructos procedeu-se a calcular as correlações entre eles. Os resultados alcançados se exibem na Tabela 01, onde se confirmam as associações existentes entre os controles internos com o desempenho percebido. 


\begin{tabular}{l|l|l|l|l|l|l|l|l|l|l}
\hline $\begin{array}{l}\text { Escores } \\
\text { fatoriais }\end{array}$ & \multicolumn{2}{l|}{ CR1 } & \multicolumn{2}{l|}{ CR2 } & \multicolumn{2}{l|}{ CP1 } & \multicolumn{2}{l|}{ CP2 } & \multicolumn{2}{ll}{} \\
\hline $\mathrm{D} 1$ & 0,5966 & $\mathrm{p}=0,000$ & 0,2427 & $\mathrm{p}=0,046$ & 0,4856 & $\mathrm{p}=0,000$ & 0,3955 & $\mathrm{p}=0,001$ & $-0,1729$ & $\mathrm{p}=0,158$ \\
\hline $\mathrm{D} 2$ & 0,3919 & $\mathrm{p}=0,001$ & $-0,2472$ & $\mathrm{p}=0,042$ & 0,4597 & $\mathrm{p}=0,000$ & 0,1507 & $\mathrm{p}=0,220$ & 0,4403 & $\mathrm{p}=0,000$ \\
\hline
\end{tabular}

Tabela 01 - Correlações entre os escores fatoriais dos constructos contas a receber (CR), contas a pagar (CP) e desempenho (D). Os números a seguir das siglas indicam o fator correspondente

Analisando os resultados da Tabela 01 pode-se dizer que ambas as relações entre os conhecimentos sobre contas a receber (CR1 e CR2) se relacionam de modo positivo e significativamente com o desempenho no que diz respeito ao tratamento com os clientes, os objetivos financeiros e com o lucro (D1). Já para o desempenho expresso pelo segundo fator, que se vincula com as vendas totais e as metas de emprego e pessoal, enquanto o CR1 o faz de forma positiva, incluindo procedimentos de segurança, direitos e conciliações, o CR2, que é associado aos recebimentos, tem associação negativa. Isto significa que os que os respondentes que declararam ter melhores desempenhos do que seus concorrentes são os que menos conhecem sobre como se procede com os recebimentos.

No caso do constructo contas a pagar, a correlação dos escores fatoriais derivados do primeiro fator (CP1) com aqueles do desempenho, D1 e D2, possuem valor positivo e significante, mas para os escores gerados pelo fator $2(\mathrm{CP} 2)$ esse tipo de relação ocorre somente com D1, sendo não significante para D2. No caso dos escores derivados do fator $3(\mathrm{CP} 3)$ as relações se invertem, isto é, são positivas e significantes para D2 e não significativas para D1. A interpretação dessas relações demonstra que os gestores que conhecem que sobre a necessidade de ter autorização para pagar com juros ou sobre o requerimento das assinaturas para efetuar os pagamentos são os que mostram correlação positiva com D1. Já os que sabem sobre as conciliações periódicas de contas a pagar com a contabilidade e da necessidade de autorização para a inclusão de compromissos são os que têm associação positiva com D2.

\section{Considerações Finais}

Esta pesquisa teve a finalidade de analisar os controles internos financeiros e seu relacionamento com o desempenho organizacional nas empresas do segmento de moda íntima e linha praia estabelecidas em Ilhota, Santa Catarina. Devido à necessidade que tem as organizações de ter crescimento persistente ou vantagem competitiva, no âmbito do mercado em que operam, precisam dispor de mecanismos eficientes que ajudem a ter sucesso nos negócios. Neste sentido a auditoria interna possui uma função primordial ao melhorar a segurança e a rentabilidade das operações das empresas, possibilitando avaliar riscos e auxiliar na tomada de decisões.

O controle interno compreende um conjunto de métodos e procedimentos que visa proteger os ativos, produzir dados contábeis confiáveis e auxiliar a administração na condução ordenada dos negócios, evitando fraudes e facilitando na tomada de decisão. Na gestão empresarial, a falta de organização causa impactos negativos tanto em termos de lucratividade quanto de imagem, influenciando desta forma, no desempenho da entidade. O controle interno financeiro precisa fazer parte da rotina das entidades. Para uma gestão eficaz torna-se necessário o seu acompanhamento diário, pois se trata de um processo contínuo importante. 
Levando em conta essas considerações o objetivo geral do estudo foi analisar se os controles internos das contas a receber e a pagar das empresas são conhecidos e se se relacionam com o desempenho organizacional. Para tanto se verificou se os controles que as firmas utilizam nas contas a receber e a pagar são feitos de acordo com as normas da auditoria, o que constituiu o primeiro objetivo específico.

Com base nos resultados obtidos a partir dos questionários aplicados, foi possível observar que as empresas entrevistadas possuem um sistema de controle interno, porém alguns quesitos devem ser observados e reavaliados, seja nas contas a receber, bem como nas contas a pagar. Os responsáveis pelos pagamentos/recebimentos e as conciliações, em grande parte das empresas, são os mesmos. Este ato vai contra as normas, pois a probabilidade de uma conferencia errônea é muito grande e para evitar erros ou fraudes, devem-se dividir as funções.

De 30 questões aplicadas, 21 obtiveram percentuais acima de 50\%. Quanto às empresas os percentuais médios de conhecimento tanto para contas a receber como a pagar foi de $60 \%$, com máximos de $73,3 \%$ para as contas a receber e de $66,6 \%$ para as contas a pagar. Esses valores, embora não sejam ótimos, constituem um sinal positivo.

Instigados por esses valores procurou-se saber se os respondentes que tem concluído, abandonado ou estão cursando o ensino superior tinham melhor índice de acertos. Os resultados não confirmaram diferenças ao avaliar a totalidade das questões, porém nas porcentagens comparadas individualmente observa-se que em 10 das quinze questões referidas às contas a receber e em 13 das outras quinze das contas a pagar, os valores de acertos foram maiores para esse grupo de respondentes.

O desempenho das empresas, atendendo ao segundo objetivo específico, se quantificou por meio de medidas subjetivas, usando-se um questionário que comparava a performance da firma do respondente com a do seu concorrente mais próximo. O emprego de escalas Likert de concordância para esta forma de mensura-lo é amplamente empregado nas pesquisas, em especial nos estudos das micro e pequenas empresas (HOQUE, 2005). Para ter medidas que sintetizassem tanto o emprego dos controles das contas a receber e a pagar assim como do desempenho, houve necessidade de utilizar um artifício. Para tanto foram geradas novas variáveis utilizando o modelo fatorial, que segundo Tabachnick e Fidel (2001) é um meio indicado para ser utilizado em outros procedimentos estatísticos, como o uso do modelo de correlação ou regressão.

Ao dispor dos escores fatoriais gerados pela análise fatorial de correspondências foi possível responder ao objetivo geral do trabalho ao calcular a correlações entre as novas variáveis que representam aos três constructos. Da análise dos resultados se conclui que existe associação, mas enquanto é positiva e significante para a relação entre os escores do constructo contas a receber e os do desempenho mensurado pelo tratamento com os clientes, os objetivos financeiros e com o lucro (D1), não ocorre o mesmo para o desempenho expresso pelas vendas totais e o cumprimento das metas de pessoal e emprego (D2), pois se bem os escores derivados do primeiro fator (CR1) continua sendo positivo aqueles provindos do segundo fator (CR2) têm correlação negativa.

As associações dos escores fatoriais do constructo contas a pagar com o desempenho mostram que os derivados do primeiro fator (CP1) tem correlação positiva e significante com os derivados de ambos os fatores extraídos para o desempenho: D1 e D2. Por sua vez, estes se 
correlacionam de igual maneira, positiva e significativamente, com CP2 e CP3 respectivamente.

Sugere-se para estudos futuros analisar se a orientação empreendedora dos proprietários e gestores influencia na adoção de sistemas de controle interno e suas relações com o desempenho organizacional.

\section{Referências}

AICPA - American Institute of Certified Public Accountants. (2016, December). An Examination of an Entity's Internal Control Over Financial Reporting That Is Integrated With an Audit of Its Financial Statements. AT Section 501. Disponível em: http://www.aicpa.org/Research/Standards/AuditAttest/DownloadableDocuments/AT00501.pd f. Acesso em: 08 set. 2019.

BARBOSA, L. F. G.; SANTOS, O. M. dos. O controle interno como ferramenta gerencial nas pequenas e médias empresas: uma análise por meio da percepção dos contadores. Pensar Contábil, v. 21, n.74, p. 4-13, 2019.

BORTOLUZZI, S. C.; ENSSLIN, S. R. ENSSLIN, L. Avaliação de desempenho dos aspectos tangíveis e intangíveis da área de mercado: estudo de caso em uma média empresa industrial. Revista Brasileira de Gestão de Negócios, v. 12, n. 37, p. 425-446, 2010.

CREPALDI, S. A.; CREPALDI, G. S. Auditoria contábil. 10 ed. São Paulo: Atlas, 2017.

DOYLE, J. T.; GE, W.; MCVAY, S. Accruals quality and internal control over financial reporting. The Accounting Review, v. 82, n. 5, p. 1141-1170, 2007.

FOURIE, H.; ACKERMANN, C. The impact of COSO control components on internal control effectiveness: an internal audit perspective. Journal of Economic and Financial Sciences, v. 6, n. 2, p. 495-518, 2013.

GARCIA, O. P. G.; KINZLER, L.; ROJO, C. A. Análise dos sistemas de controle interno em empresas de pequeno porte. Interface - Revista do Centro de Ciências Sociais Aplicadas. v. 11, n. 2, p. 133-153, 2014.

HOQUE, Z. Linking environmental uncertainty to non-financial performance measures and performance: a research note. The British Accounting Review, v. 37, p. 471-481, 2005.

JOKIPII, A. Determinants and consequences of internal control in firms: a contingency theory based analysis. Journal of Management \& Governance, v. n. 2, p. 115-144, 2010.

LEITE, D. U.; PINHEIRO, L. E. T. Percepção dos auditores independentes e auditados sobre a aplicação da Lei Sabanes Oxley nos controles internos. Anais... IX Congresso ANPCONT. Curitiba: [s.n.]. 2015. p. 1-19.

LOPES, I. M. de O.; MARQUES, V. A.; LOUZADA, L. C. Deficiências dos controles internos das empresas listadas na [B3]. Revista Evidenciação Contábil e Finanças, v. 7, n. 3, p. 105, $126,2019$. 
MACEDO, M. A. S.; CORRAR, L. J. Análise do desempenho contábil-financeiro de seguradoras no Brasil no ano de 2007: um estudo apoiado em Análise Hierárquica (AHP). Contabilidade Vista \& Revista, v. 21, n. 3, p. 135-165, 2010.

MACHADO, M. M.; MACHADO, M.A.; HOLANDA, F. M. da. Indicadores de desempenho utilizados pelo setor hoteleiro da cidade de João Pessoa/PB: um estudo sob a ótica do Balanced Scorecard. Revista Turismo Visão e Ação, v.9, n.3, p.393-406, 2007

MELNYK, S. A.; BITITCI, U.; PLATTS, K.; TOBIAS, J; ANDERSEN, B. Is performance measurement and management fit for the future? Management Accounting Research, v. 25, n. 2, p. 173-186, 2014.

NASCIMENTO, S. do; BORTOLUZZI, C. S.; DUTRA, A.; ENSSLIN, S. R. Mapeamento dos indicadores de desempenho organizacional em pesquisas da área de Administração, Ciências Contábeis e Turismo no período de 2000 a 2008. Revista de Administração. v. 46, n. 4, p. 373-391, 2011

NEELY, A. D.; ADAMS, C.; KENNERLEY, M. The performance prism: the scorecard for measuring and managing business success. London: Financial Times/Prentice Hall. 2002.

POSTIGLIONE, E. M.; SILVA, D. Uso efetivo de controles internos em uma microempresa de Santa Maria: Fundamentos para o crescimento e a manutenção do negócio. In: $1^{\circ}$ Congresso de Contabilidade da UFRGS, 2016, Anais ... Porto Alegre, 2016

RITA, C. de O. Análise comparativa do controle interno no contas a receber e a pagar nas empresas Beta Ltda. e Alfa Ltda. Revista Catarinense da Ciência Contábil - CRCSC, v. 9, n. 26, p. 63-78, 2010.

SEVERINO, A. J. Metodologia do trabalho científico. São Paulo: Cortez, 2000.

TABACHNICK, B. G.; FIDEL, L. S. Using Multivariate Statistics. 4. ed. Boston: Allyn and Bacon, 2001.

TYSIAC, K. Internal control, revisited: prominent COSO officials discuss proposed updates to framework. Journal of Accountancy, v.3, n. 24, 2012.

VERGARA, S. C. Projetos e relatórios de pesquisa em administração. São Paulo: Atlas, 1998. 